\title{
Telehealth technology: An emerging method of delivering pulmonary rehabilitation to patients with chronic obstructive pulmonary disease
}

\author{
Dina Brooks PhD MSc BScPT
}

$\mathrm{T}$ elehealth is an emerging method of delivering health services, including rehabilitation, to patients (1). In the current issue of the Canadian Respiratory Journal (pages 216-220), Stickland et al (2) examined the efficacy of an outpatient pulmonary rehabilitation (PR) program delivered via Telehealth technology (Telehealth-PR) and compared it with PR delivered in person through a standard outpatient, hospital-based program. Using a parallel group, noninferiority experimental design, the authors demonstrated that the two programs resulted in similar improvements in quality of life and functional capacity.

Telehealth is an option particularly for those living in isolated areas or who are unable to access transportation to hospital or outpatient programs (3). Although there is some evidence to support Telehealth in chronic obstructive pulmonary disease (COPD), there is little information regarding the delivery of rehabilitation in this population. With respect to Telehealth, Polisena et al (4) completed a systematic review of 10 articles describing 858 patients with COPD. Four studies compared home telemonitoring with usual care, while six randomized controlled trials compared telephone support with usual care. There was considerable variability among studies in terms of interventions and approach. The results showed that home Telehealth (home telemonitoring and telephone support) decreased the rates of hospitalization and emergency department visits, while findings for hospital bed days of care varied among studies. Another systematic review of this topic by Bartoli et al (5) reported that telemonitoring, consisting of routine data transmission between the patient's home and a healthcare professional located in the hospital, was the most common service provided by Telehealth in individuals with COPD.

Within the realm of rehabilitation, Lewis et al (6) examined whether telemonitoring after PR impacted health care use. They randomly assigned patients who had completed at least 12 sessions of outpatient PR who were also stable with moderate to severe COPD to receive standard care or telemonitoring. Health care professionals could access the data and receive alerts if there were concerns. There were fewer primary care contacts for respiratory issues in the Telehealth group, but no differences between the groups in emergency room visits, hospital admissions, days in hospital or contacts to the specialist COPD community nurse team.
The trial by Stickland et al (2) is unique in that it addressed the delivery of PR rather than simply monitoring it. The individuals in the Telehealth-PR program were assessed by teleconferencing for their suitability for PR. They subsequently attended PR twice a week for eight weeks within their local community where they performed group exercises for $2 \mathrm{~h}$ and received education (via teleconferencing) for $1 \mathrm{~h}$. The patients exercised in groups of two to six, and were supervised by a local health care professional. This model has the potential to increase accessibility to PR, especially for those in isolated areas with no access to large centres, but still allowing social interaction provided by a group setting and supervision from a health care professional.

In summary, the results of the study by Stickland et al provide evidence in support of one Telehealth model for the delivery of PR. Future studies are needed to examine the long-term efficacy of this intervention after one year and beyond, and to explore other Telehealth models, possibly within the home, for delivery of rehabilitation.

\section{REFERENCES}

1. McCue M, Fairman A, Pramuka M. Enhancing quality of life through telerehabilitation. Phys Med Rehabil Clin N Am 2010;21:195-205.

2. Stickland MK, Jourdain T, Wong EYL, Rodgers WM, Jendowsky NG, MacDonald GF. Using Telehealth technology to deliver pulmonary rehabilitation to patients with chronic obstructive pulmonary disease. Can Respir J 2011;18:4:216-20.

3. Jenkins S, Hill K, Cecins NM. State of the art: How to set up a pulmonary rehabilitation program. Respirology 2010;15:1157-73.

4. Polisena J, Tran K, Cimon K, et al. Home telehealth for chronic obstructive pulmonary disease: A systematic review and meta-analysis. J Telemed Telecare 2010;16:120-7.

5. Bartoli L, Zanaboni P, Masella C, Ursini N. Systematic review of telemedicine services for patients affected by chronic obstructive pulmonary disease (COPD). Telemed J E Health 2009;15:9:879-83.

6. Lewis KE, Annandale1 JA, Warm DL, et al. Does home telemonitoring after pulmonary rehabilitation reduce healthcare use in optimized COPD? A pilot randomized trial. J Chron Obstr Pulmon Dis 2010;7:44-50.

Department of Physical Therapy, University of Toronto, Toronto, Ontario

Correspondence: Dr Dina Brooks, Department of Physical Therapy, University of Toronto, 160-500 University Avenue, Toronto,

Ontario M5G 1V7. Telephone 416-978-1739, fax 416-946-8562, e-mail dina.brooks@utoronto.ca 


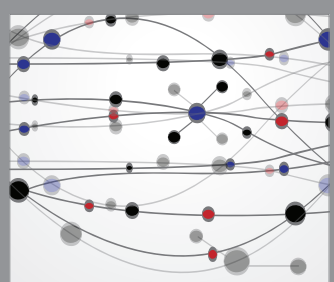

The Scientific World Journal
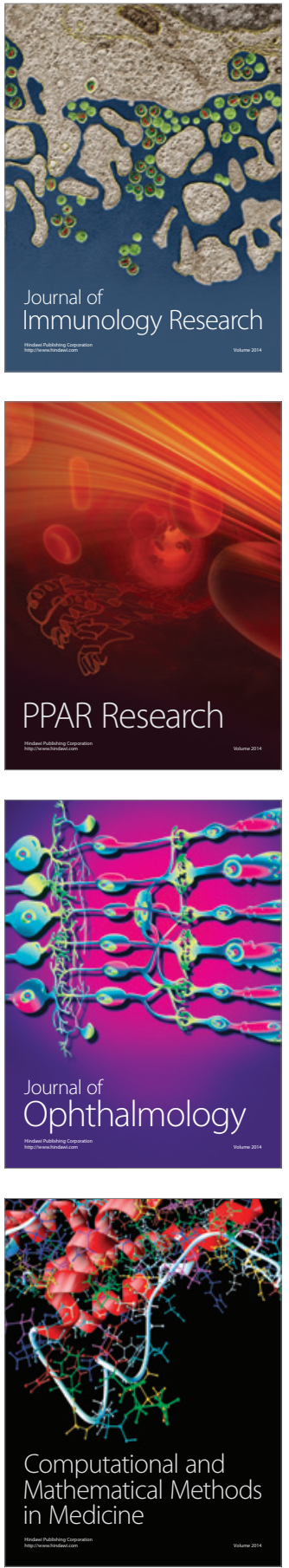

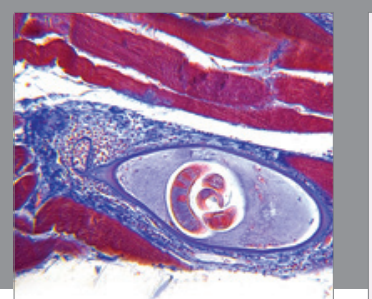

Gastroenterology Research and Practice

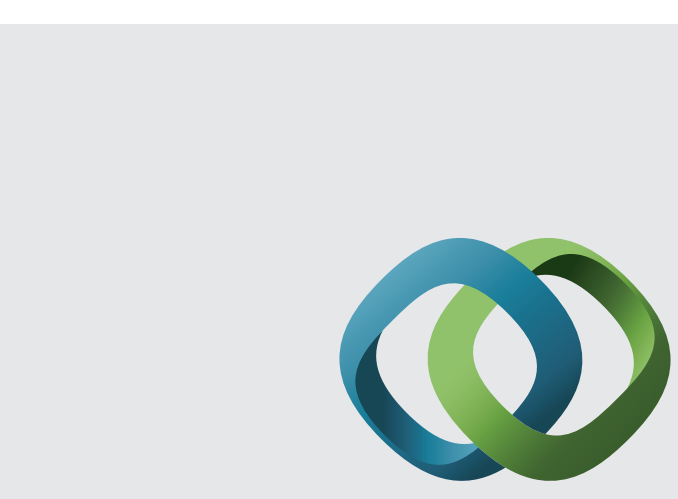

\section{Hindawi}

Submit your manuscripts at

http://www.hindawi.com
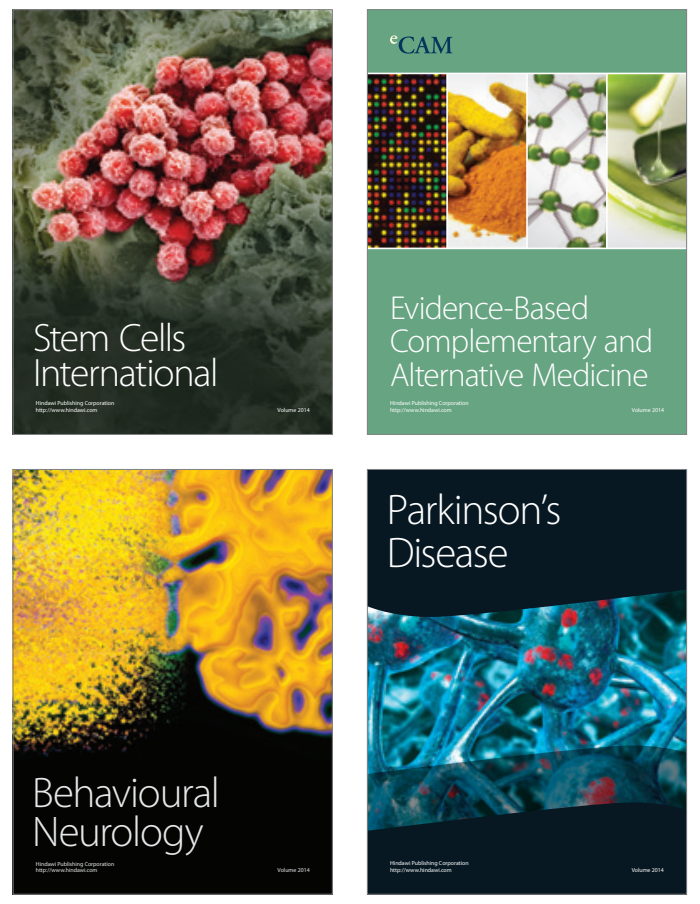
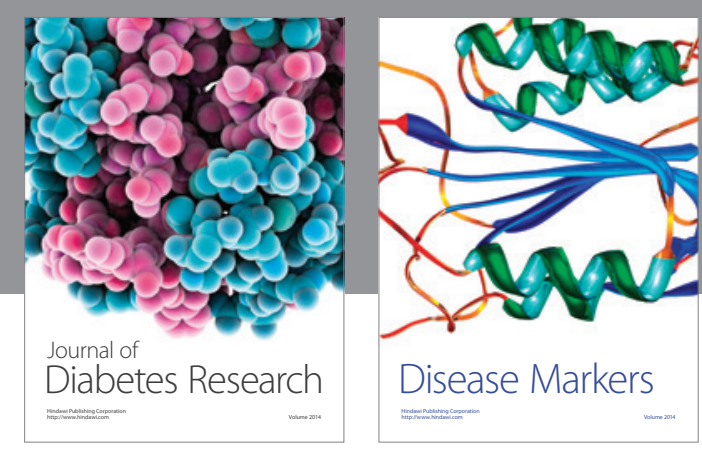

Disease Markers
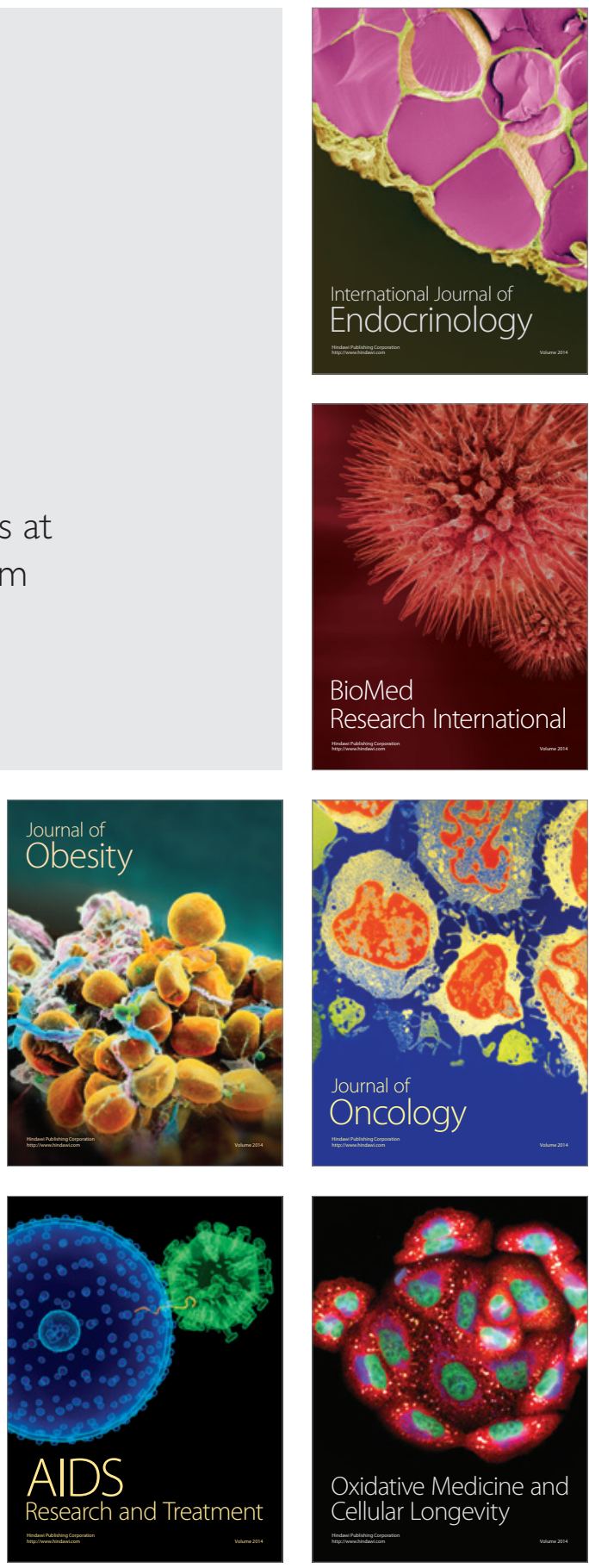